\title{
Las estrellas son negras: un clásico afroamericano ${ }^{59}$ Las estrellas son negras: An Afroamerican classic.
}

\author{
Óscar Collazos
}

Recibido: 1 de Marzo 2011. Aprobado: 10 de Abril de 2011

\begin{abstract}
Resumen
La recuperación de Arnoldo Palacios y de sus obras para el canon de la literatura afroamericana le sitúa como un escritor esencial en la construcción de una identidad cultural de los colombianos y de una literatura fiel a su destino social. Sus personajes negros, exponiendo las precariedades de su situación, no apelan en ningún instante a la piedad ni a la conmiseración, y sí construyen un imaginario de denuncia política y social.
\end{abstract}

Palabras clave: Arnoldo Palacios; Novela afroamericana; Las estrellas son negras; Buscando a mi madredios.

\begin{abstract}
The recovering of Arnoldo Palacios and his works to the canon of afroamerican literature places him as an essential writer for the construction of a cultural identity for Colombian people and a faithful literature to its social destination. His black characters, exposing the precariousness of their situation, at any time does not appeal to pity or sympathy, but construct an imaginary of political denunciation and social criticism.
\end{abstract}

Keywords: Arnoldo Palacios; Afroamerican novel; Las estrellas son negras; Buscando a mi madredios.

Arnoldo Palacios nació en 1924 en Cértegui, departamento del Chocó, región selvática cuyo trazado, en el noroeste de Colombia, es un complejo sistema selvático de bosque húmedo en la cordillera del Darién, con costas en el océano Pacifico y el mar Caribe, en el extremo norte, cerca del Golfo de Urabá. La región está atravesada por los caudalosos ríos Atrato y San Juan, arterias de comunicación que sirvieron siempre a las migraciones internas.

Los casi 47 mil kilómetros cuadrados del departamento, recién creado en 1947, no eran de fácil acceso desde o hacia el resto del país. Esta circunstancia volvía más dramático el aislamiento de la región, considerada una de las más lluviosas de la tierra.

\footnotetext{
${ }^{59}$ Artículo derivado del proyecto de investigación Biblioteca Afrocolombiana, patrocinado por el Ministerio de Cultura de Colombia, del cual el autor hizo parte en la preparación, organización y estudio de la narrativa del escritor chocoano Arnoldo Palacios.
} 
La existencia de Cértegui, el pueblo donde nació Arnoldo Palacios, se remonta a 1775. En su página oficial de Internet, se dice que "como casi todos los pueblos del Chocó, surge inicialmente con la construcción de unas pocas casas de paja, alrededor de un campamento minero, bajo la dirección de Matías Tres Palacios(...), quien por esas circunstancias aparece como fundador de lo que hoy es el Municipio de Cértegui."

Por esta razón, la historia del pueblo está ligada a este apellido, "cuyo tronco principal comprende las familias: Andrés, Lucas, Juan de la Cruz , Juan Pablo, María Encarnación, Salvador, Francisco, Carlos, Miguel de los Santos, Jeremías, Juan José y Nepomuceno Palacios, de los cuales se han desprendido varias generaciones que se han venido cruzando hasta nuestros días." Desde entonces, las ramificaciones del apellido dominan los libros del registro civil, como si se tratara de una comunidad endogámica, hasta el punto de que cualquier averiguación sobre la familia del escritor conduce siempre a parentescos cercanos o remotos.

A los 15 años de edad, Arnoldo se trasladó de Cértegui a Quibdó para continuar sus estudios. No es difícil imaginar su viaje por trochas y ríos ni admirar la entereza del joven humilde, obsesionado ya con la idea de ser "alguien” distinto. La poliomelitis que empezó a aquejarlo desde los dos años de edad, lo obligó a hacer grandes esfuerzos para moverse, pero esta circunstancia no fue un obstáculo en su vida. El joven continuó sus estudios de bachillerato en el Colegio Carrasquilla, de la capital del departamento.

En 1943 viajó con una beca a Bogotá y terminó sus estudios de secundaria en el Colegio Camilo Torres, donde se ganó el cariño y la admiración de su rector, el humanista José María Restrepo Millán. Pocos años después, cuando Palacios publicó su primera novela, los comentarios de Restrepo Millán alentarían la carrera literaria del joven.

Regresó por un tiempo a Quibdó, decidido a fortalecer la vocación que lo había llevado a escribir relatos cortos y una obra de teatro sobre Manuel Saturio Valencia, el último colombiano fusilado legalmente por motivos que todavía son tema de discusión y fuente de inspiración de historiadores y novelistas, sacrificio en el cual los chocoanos siguen viendo la mano de una grande injusticia, cometida desde la ley. Los afrodescendientes del Chocó siguen viendo en Manuel Saturio Valencia un ejemplo de lucha por las igualdades étnicas.

A propósito de esta obra teatral, se cuenta una anécdota curiosa. Al parecer, Arnoldo Palacios se propuso ponerla en escena con actores naturales, es decir, gente del común sin

Poligramas 35, primer semestre 2011, ISSN 0120-4130. 
experiencia en las tablas, pero el rumor de que los blancos de la capital pondrían una bomba en el teatro, les hizo cancelar el estreno de la pieza. Este episodio y, probablemente, la realidad vivida en su pueblo desde la infancia, se reflejan en la actitud intelectual y obras literarias de Palacios. Alimentan una conciencia étnica que no lo abandonará en toda la vida.

Años después, cuando Palacios se encuentre en París, dicha conciencia se verá mucho mejor y más profundamente "argumentada" gracias a las relaciones que establece con los escritores africanos y antillanos agrupados alrededor de la revista Présence Africaine. El escritor relativamente provinciano que madura su formación intelectual en el exilio europeo, conocerá de cerca a escritores antillanos y africanos, poetas, ensayistas, novelistas destacados de una corriente liberadora conocida con el nombre de "negritud", forjada en el pensamiento anticolonial de los años 50 y 60 . Uno de los libros fundamentales en esa toma de conciencia fue, sin duda, Los condenados de la tierra, del martiniqués Franz Fanon.

En Colombia, antes de viajar a Francia, Palacios no sabe nada de la existencia de Aimé Césaire y Leopold Seddar Senghor; no conoce la obras de Jacques Stephen Aléxis ni Jacques Roumain; ni siquiera conoce la poesía de su contemporáneo René Depestre, autores que forjan la "negritud" que va a encontrar ya formulada en el París de los años 50, en algunos casos apoyada en la militancia comunista. París es, como para muchos escritores, el lugar desde donde se "descubren” las raíces latinoamericanas.

La conciencia del escritor en ciernes está dominada por un sentimiento de justicia y rebeldía razonada, por la indignación que nace de las desigualdades sociales conocidas por él desde la infancia, y por la postración material de los afrodescendientes de su región, pobladores, desde siempre, de vastas regiones explotadas por colonos blancos y compañías extranjeras.

El escritor Alfonso Carvajal recuerda que, en 1947, Palacios está de vuelta en la capital del país. "Vive humildemente, pero la literatura le da fuerzas para vencer obstáculos casi imposibles." Conoce a otros jóvenes escritores de su generación, entre ellos a Gabriel García Márquez, Manuel Zapata Olivella y Enrique Buenaventura; conoce y lee a los poetas del movimiento "Piedra y Cielo", se familiariza con la poesía de Jorge Artel y traba amistad con el providencial Carlos Martín, quien "le permite utilizar la máquina de escribir del despacho del Ministerio de Educación” donde Arnoldo trabaja en su novela. Allí, en 
máquina de escribir y oficina prestadas, Palacios se desvela desde el año anterior en la escritura de su novela Las estrellas son negras. La termina el 8 de abril de 1948.

La fecha carecería de importancia si al día siguiente no se hubiera producido en la capital de la República un hecho que cambió para siempre la vida de la ciudad y el rumbo político del país, determinando de igual manera un cambio de rumbo en la novela colombiana de la época.

Aceptemos entonces que Palacios perdió los originales de su novela aquel día trágico, en circunstancias parecidas a las que vivió García Márquez tratando de salvar su máquina de escribir.

El 9 de abril -refiere Carvajal- el pueblo lastimado saquea el centro de Bogotá y el edificio Cadena es incendiado. La novela de Palacios es un montón de cenizas que la efímera insurrección se llevó. En medio de la conmoción nacional, el escritor vive su propia desgracia. Algunos amigos, entre ellos el profesor Cardona Londoño, le dan ánimos para reconstruir el libro, y con el arma ferviente de la memoria lo rehace en dos semanas.

La historia que rodea la reescritura de esta novela es digna de un pie de página. Pocas veces en la historia de la literatura, las obras perdidas en accidentes inesperados consiguen ser reescritas y satisfacer al escritor. No sucedió lo mismo con Las estrellas son negras. Poco después, por mediación de Zapata Olivella (uno de los escritores más generosos que haya conocido la literatura colombiana), los originales de la novela cayeron en manos del editor y escritor español Clemente Airó, un exiliado de la guerra civil que había fundado y dirigía la Editorial Iqueima.

La novela -cuenta Carvajal- recibió "la bendición crítica de Ulises (Eduardo Zalamea), escritor y director del suplemento literario de El Espectador, el mismo suplemento donde Gabriel García Márquez había publicado, en 1947, “La tercera resignación”, el primero de sus cuentos.

Palacios obtiene entonces una beca para estudiar lenguas clásicas en la Sorbona. En septiembre de 1949, viaja desde Cartagena de Indias a Francia acompañado por la discreta gloria de los 500 ejemplares impresos de su primera novela. García Márquez, que entonces es un joven periodista de El Universal y la promesa más célebre de la novela colombiana, saluda efusivamente el paso del escritor Palacios por la ciudad. Lo ha conocido en la turbulenta Bogotá del año anterior. 
En adelante, poco se sabrá del escritor. Se sabe que vive en Francia, que ha visitado los países de la llamada Cortina de Hierro, que su novela ha sido traducida en varios idiomas; se sabe que vive con una aristócrata en las afueras de París, que ha escrito otras novelas, pero la precariedad del mundo editorial colombiano no registra la aparición de las nuevas obras. Nada se sabrá, como no sea por referencias bibliográficas, de la existencia de dos libros publicados en francés: Les mamelles du Choco y La foret de la pluie.

Conocí personalmente a Palacios en 1966, en una reunión de escritores promovida por Zapata Olivella. Yo era un joven escritor que se sorprendía ante la firmeza de los argumentos de Palacios, sobre todo aquellos que se referían a la identidad cultural de los colombianos y al camino que "debía” seguir la literatura para ser fiel a su destino social. Palacios al igual que su amigo Zapata Olivella defendía la idea de una "literatura nacional” y se mostraba fiel a la idea del "compromiso" expuesta por Jean-Paul Sartre. Se lamentaba discretamente y con razón del olvido a que estaba sometida su obra.

Una nueva generación de escritores -a la cual pertenezco y que se formó hacia finales de los años 60 del siglo pasado- sabía de la existencia de Las estrellas son negras pero casi nadie la había leído ni la obra se encontraba en librerías. Habían pasado cosas importantes en la literatura colombiana y el regreso de Palacios parecía el de un hijo pródigo, desconocido por todos.

La "modernización" de la prosa novelística, evidente en las primeras novelas de García Márquez (La hojarasca y El coronel no tiene quien le escriba, de 1955 y 1959, respectivamente); el tránsito dado de la poesía a la novela por el Héctor Rojas Herazo de Respirando el verano (1962); los cuentos y la novela posterior de Cepeda Samudio (Todos estábamos a la espera y La casa grande); la obra narrativa y crítica de Hernando Téllez y otros narradores de la generación de Palacios; la poesía narrativa de Álvaro Mutis; las novelas "rurales" y hondamente humanas de Eduardo Caballero Calderón (sobre todo Siervo sin tierra); el salto que estaba dando la narrativa de Manuel Mejía Vallejo para superar el costumbrismo de sus orígenes y darle una nueva dimensión a los conflictos del campo colombiano (El día señalado, 1964).

Ya las crónicas y novelas de José Antonio Osorio Lizarazo habían hecho el tránsito del campo a la ciudad (El hombre bajo la tierra de 1944 y El día del odio, de 1952), dando 
paso al realismo urbano de La calle 10 (1962) y Chambacú: corral de negros (1963), pero, sobre todo, a la madurez de En Chimá nace un santo (1964), de Zapata Olivella.

En fin, el inventario de época, que es el inventario de 15 o 20 años de narrativa colombiana, podrían cerrarlo las novelas de Arturo Echeverri Mejía (Bajo Cauca y Hombres de Talara), pero, sin duda, el vacío grande lo constituye la ausencia de Las estrellas son negras en el inventario crítico de la novela colombiana del primer medio siglo.

En sus apariencias, la obra de Arnoldo Palacios parecía inscribirse en un realismo tradicional, de corte costumbrista. Pese a ser escrita en una década en la que el llamado "realismo social" rendía un triste tributo al llamado "realismo socialista", de marcados tintes militantes e ideológicos, la obra de Palacios va más allá de esta tendencia, cultivada con más infortunio que aciertos por algunos escritores de propósitos políticos. Es muy posible que si la experiencia individual y social de Palacios no hubiera dejado huellas tan profundas, la sensibilidad social del escritor se hubiera orientado hacia el lugar común de entonces: dar cuenta de la violencia política que se vivía en los campos de Colombia.

La llamada "novela de la violencia" quedaba atrás como un importante episodio de la crónica, empobrecida a veces por la moral civil de los escritores que no pudieron sustraerse a la tragedia y al inventario de sus crueldades, al sello de una intolerancia que sumió al país en una guerra que duró de 1948 a 1957. La renovación literaria y ética que propuso, por ejemplo, la revista Mito, con Jorge Gaitán Durán a la cabeza, parecía cerrar el capítulo de la "novela de la violencia", pero lo hacía cometiendo algunas injusticias. El problema no era la violencia sino la manera de expresarla desde la literatura. Pero Palacios estaba fuera de Colombia y al margen de este debate.

Una injusticia de índole estrictamente literaria: suponer que el habla popular, reproducida de manera significativa en los diálogos de ciertas novelas, las afiliaba al costumbrismo. Éste parecía ser el "pecado" de Las estrellas son negras: que el narrador pusiera a hablar a sus personajes remedando el habla de su condición social. Pero no había tal pecado: el habla popular era un esfuerzo por dar a la novela una mayor verosimilitud, una convención del realismo que el costumbrismo había llevado a sus excesos.

Y Palacios, al concebir el personaje del joven Irra, no sólo evitaba los excesos verbales de una mirada patética o piadosa, sino que ponía al personaje a hablar desde el interior de su

Poligramas 35, primer semestre 2011, ISSN 0120-4130. 
tragedia. La narración objetiva, lacónica como una cámara, tenía su contrapunto en las voces de los personajes. Ese es el equilibrio que mantiene durante toda la novela.

La psicología de Irra, el personaje central, se introduce en sus reacciones fisiológicas. En esta especie de somatización gradual del hambre y la humillación, Irra deja de ser el personaje de una crónica exterior para convertirse en arquetipo de la tragedia. Lo que nos conmueve en las veinticuatro horas de su joven vida no es tanto la pobreza sino los estragos mentales que provoca, de la postración anímica hasta la confusión de la ira. El espacio irrisorio donde sobrevive, narrado en detalle por Palacios, traza una frontera simbólica entre la ciudad próspera y la ciudad miserable. Cuando el amor parece redimirlo de tanta miseria y se consuma el encuentro amoroso con la joven Nive, sobreviene otra tragedia.

Encerrado en una realidad que se vuelve circular, Irra concibe la fuga, pero es víctima de la fatalidad: no podrá huir de su entorno, no podrá subir al barco que lo lleve a Cartagena de Indias. "Las ruinas circulares" de su realidad parecen arrojarlo a una sin salida. Es cuando la novela, más que perfilarse como producto del pesimismo, se vuelve expresión de un destino trágico.

La crítica y los lectores de la época no advirtieron la densidad de este conflicto. Tampoco advirtieron la maestría de la narración objetiva. Un ejemplo: “Contra uno de los ángulos de la cocina, hacia el río, el fogón, armatoste de barro, tosca mampostería de madera, ocupando la mitad del fogón se levantaba el horno, cúpula de barro fino." Otro: "Por la mitad de la cocina, a la altura de la cabeza, pasaba un alambre del cual pendían piezas de ropa mojada, cuya agua se escurría trazando una línea húmeda en el piso.”

Ese laconismo, tal vez con un sello de época, es el mismo que encontraremos en El coronel no tiene quien le escriba, de García Márquez, y La casa grande, de Cepeda Samudio. Lo importante no es la coincidencia sino el cambio que se está operando en la retórica de la novela colombiana.

Los críticos de la época y los autores de muchos manuales de literatura colombiana ignoraron las características literarias de esta novela: la parquedad de su lenguaje, la expresión poética de la miseria, el cuidado extremo que puso el escritor al evitar el panfleto, es decir, la condena moral o política explícitas. Olvidaron algo que parecía haber calado hondo en la concepción de la novela como "crónica y autobiografía", por usar la afortunada expresión de Gerard Genette: que todo personaje reclama una autonomía

Poligramas 35, primer semestre 2011, ISSN 0120-4130. 
distinta a la vida y pensamientos del escritor que lo concibe. Los personajes deben condenar o salvar desde sus propias experiencias.

La novela de Palacios, dividida en cuatro capítulos o libros, sigue la trayectoria de su personaje y de los personajes secundarios que acompañan en un día su experiencia vital, los signos exteriores de su tragedia. La ciudad, en su precariedad urbanística, está tan presente como las orillas del río majestuoso. Las experiencias humillantes se suman una a otra, pero el narrador de Las estrellas son negras no apela en ningún instante a la piedad ni a la conmiseración.

La novela del siglo XX conocía, por ejemplo, la expresión literaria del hambre en escritores como Knut Hansum. Conocía el infierno de las miserias en las novelas de Curzio Malaparte $\mathrm{y}$, por supuesto, las cortes de los milagros que aparecían en las novelas realistas del indigenismo americano: Huasipingo de Jorge Icaza, El mundo es ancho y ajeno, de Ciro Alegría, etc. No se conocía la experiencia individual e interiorizada del hambre, convertida en delirio de la conciencia. El hambre está en el centro de la pobreza y ésta en el corazón de un mundo de condenados a sufrirla sin que nada se esté haciendo para impedirlo.

Las buenas y grandes obras literarias sobreviven a la realidad que les dio origen. Del mundo que recrearon en profundidad puede transformarse, pueden desaparecer los seres humanos que inspiraron la trama del relato y hasta la mentalidad de época. Las obras literarias superan la realidad que les dio origen y adquieren vida propia. Sobre todo las novelas, que se escriben desde la condición humana.

Pensaba esto al aceptar la oferta que me hizo en 2006 la revista Arcadia: escribir un artículo que comparara el paisaje de la novela con el paisaje actual de la realidad, es decir, el paisaje de las miserables orillas del río Atrato, en la capital del Chocó, con el paisaje que Arnoldo Palacios había pintado en su novela. Temí que la realidad no tuviera el sello de tanta pobreza y miseria, que estos elementos sólo existieran en la novela publicada 57 años atrás. Celebré que la novela hubiera sobrevivido felizmente a las conspiraciones del tiempo y a las acechanzas del olvido, que su pesada carga documental no la hubiera convertido en simple expediente sociológico. En fin, celebré que siguiera siendo una conmovedora obra literaria. 
Lamenté con tristeza que la realidad de Quibdó, escenario de la novela, siguiera siendo la misma o acaso más perturbadora que la de hace medio siglo. Sin embargo, seguí pensando que novelas como éstas deberían sumarse al patrimonio de una cultura.

En 1971 se publicó una segunda edición colombiana de Las Estrellas son negras, pero los malentendidos de la crítica la condenaron injustamente a seguir siendo una pieza rara en el museo de la novela colombiana. La tremenda denuncia social que hay detrás de su historia, el descubrimiento de un mundo de miserias inédito en la novela de la época, la aparición del mundo afrocolombiano visto por un escritor afrocolombiano que ofrecía este expediente autobiográfico a través de un personaje magníficamente estructurado, estas y muchas otras cualidades no bastaron para recuperar esta novela del olvido e introducirla en la Academia y en el canon de la narrativa colombiana.

Lo mismo estaba sucediendo con los relatos de otro afrocolombiano, Carlos Arturo Truque, nacido en el Chocó y residente en Buenaventura. Una apreciación bastante superficial la consideraba "demasiado costumbrista", pero Truque "hablaba" de las mismas violencias con el rigor de un excelente narrador de historias trágicas y tristes. La violencia política que no aparece en las novelas de Palacios, asoma en los relatos de iQue vivan los compañeros! En 1998 se hizo de nuevo justicia con la obra de Arnoldo Palacios: el Ministerio de Cultura le hizo un homenaje y con éste se conoció otra edición de Las estrellas son negras. La edición llevaba un prólogo del periodista y escritor Antonio Cruz Cárdenas y recuperaba el texto entrañable que José María Restrepo Millán escribió para la segunda edición.

"Lo cierto es que, medio siglo después -escribía Cruz Cárdenas-, Las estrellas son negras están ahí, ahora, no sólo como relato literario de gran valor sino como testimonio de una raza, la negra, minoritaria y marginada, cuyos padecimientos de escasez, injusticia y desigualdad son comunes, también, a una gran parte de la población colombiana.”

En uno de los apartes de este prólogo se sabe un poco más de la vida personal y familiar del escritor. "Palacios ha viajado por Islandia, Rusia, Estados Unidos e Italia y desde hace veintitrés años vive en Francia con su esposa Beatriz, de nacionalidad francesa, y sus hijos Pol, Eloísa, Matías y Leopoldo”, dice el comentarista.

Una nueva edición de la novela apareció en 2007, con el sello de Intermedio Editores. Poca cosa para los 60 años de vida de un libro esencial para la literatura colombiana. La recuperación de Las estrellas son negras para el canon de la literatura colombiana ha

Poligramas 35, primer semestre 2011, ISSN 0120-4130. 
permitido conocer, en voz del propio novelista, aspectos ocultos de su vida de escritor. Palacios cree en la fidelidad del escritor a sus orígenes y condición social, insiste en la búsqueda de las propias raíces y en la estrecha relación que guardan autobiografía y creación literaria.

El reconocimiento de la Academia ha permitido que se conozcan otros libros suyos: Buscando a mi madredediós (Universidad del Valle y Ministerio de Cultura, 2009) y Cuando yo era joven, una recopilación de sus escritos periodísticos.

Cartagena de Indias, febrero de 2010 